Delft University of Technology

\title{
The Effect of Shape on the Pull-out Capacity of Shallow Plate Anchors in Sand
}

Giampa, J.R.; Bradshaw, Aaron; Gerkus, Hande; Gilbert, R.B.; Gavin, Kenneth; Sivakumar, V.

DOI

10.1680/jgeot.17.P.269

Publication date

2018

Document Version

Final published version

Published in

Géotechnique

\section{Citation (APA)}

Giampa, J. R., Bradshaw, A., Gerkus, H., Gilbert, R. B., Gavin, K., \& Sivakumar, V. (2018). The Effect of Shape on the Pull-out Capacity of Shallow Plate Anchors in Sand. Géotechnique, 69 (2019)(4), 355-363. https://doi.org/10.1680/jgeot.17.P.269

\section{Important note}

To cite this publication, please use the final published version (if applicable).

Please check the document version above.

\section{Copyright}

Other than for strictly personal use, it is not permitted to download, forward or distribute the text or part of it, without the consent of the author(s) and/or copyright holder(s), unless the work is under an open content license such as Creative Commons.

\section{Takedown policy}

Please contact us and provide details if you believe this document breaches copyrights.

We will remove access to the work immediately and investigate your claim. 
Green Open Access added to TU Delft Institutional Repository 'You share, we take care!' - Taverne project

\section{https://www.openaccess.nl/en/you-share-we-take-care}

Otherwise as indicated in the copyright section: the publisher is the copyright holder of this work and the author uses the Dutch legislation to make this work public. 


\title{
The effect of shape on the pull-out capacity of shallow plate anchors in sand
}

\section{J. R. GIAMPA*, A. S. BRADSHAW $\uparrow$, H. GERKUS $\ddagger$ R. B. GILBERT§, K. G. GAVIN\| and V. SIVAKUMAR}

\begin{abstract}
This paper presents an experimental and analytical study to investigate the effect of shape on the pull-out capacity of shallow horizontal plate anchors in sand under drained loading conditions. Novel dynamically penetrating plate anchor concepts have been proposed for use in the offshore energy sector. These anchor concepts may have shapes that are atypical, and the analysis of pull-out capacity of these shapes may be needed for design. Most of the research on the capacity of shallow horizontal anchors has focused on square, rectangular or circular shapes. Physical and analytical modelling was used to study the capacity of circular, square, triangular and kite-shaped plate anchors. The $1 \boldsymbol{g}$ physical model results indicated that the circular anchor had the highest capacity, which was up to two times higher than the square anchor, which had the lowest capacity of all shapes included in this study. The equilateral triangle and kite shapes had capacities that fell between the circle and the square shapes. A new generalised non-associated flow limit equilibrium model was developed to predict the pull-out capacity of shallow plate anchors with convex polygon anchor shapes. The model was most accurate at embedment ratios of 4 or less, with a bias of less than $10 \%$.
\end{abstract}

KEYWORDS: anchors \& anchorages; design; limit equilibrium methods; model tests; sands

\section{INTRODUCTION}

Production of significant amounts of renewable energy without harmful emissions is the prime target of many nations around the world (Musial \& Ram, 2010). The energy sector is very successful in tapping into onshore and offshore wind energy. However, the offshore wind industry will likely move further into deeper waters to capture strong wind resources and to minimise the visual impact of wind farms on coastal communities. The major challenges with moving into deeper waters are that conventional offshore foundations will become impractical and uneconomical because of the size required for resisting environmental forces and the energy required for installation. One possible alternative way of supporting wind farms would be to consider floating substructures anchored to the seafloor, which must provide enough buoyancy to support the weight of the turbine, and restrain from pitch, roll and heave motions within acceptable limits (Musial et al., 2006).

Floating platforms have been successfully used by the oil and gas industry operating in deep waters. These platforms are secured to the seafloor through mooring systems. The mooring systems may be taut, semi-taut, or catenary and attached to a variety of different anchors including anchor piles, suction caissons, drag anchors, suction embedded plate

Manuscript received 28 October 2017; revised manuscript accepted 11 May 2018.

Discussion on this paper is welcomed by the editor.

* GEI Consultants Inc., Woburn, MA, USA

(Orcid:0000-0002-4705-4001).

$\uparrow$ Department of Civil and Environmental Engineering, University of Rhode Island, Kingston, RI, USA.

$\$$ Freese and Nichols, Inc., Austin, TX, USA.

$\S$ Department of Civil Architectural and Environmental Engineering, University of Texas at Austin, Austin, TX, USA.

\| Faculty of Civil Engineering and Geosciences, Delft University of Technology, Delft, the Netherlands.

I School of Natural and Built Environment, Queen's University

Belfast, Belfast, Northern Ireland, UK. anchors and dynamically penetrating anchors (Randolph \& Gourvenec, 2011). Plate type anchors provide an efficient means to resist vertical and inclined loading by providing much of the resistance in bearing rather than in side shear that might be the case, for example, in an anchor pile. Side shear resistance (i.e. friction) is not as efficient as bearing resistance, and can be prone to capacity and stiffness degradation from cyclic loading (e.g. Jardine et al., 2012).

Novel dynamically penetrating plate anchor concepts for the offshore energy sector are already under development, such as the flying wing anchor (Gerkus et al., 2016) and the deep-penetrating anchor (DPA) III (Chow et al., 2017). In the first concept, a wing-shaped anchor is initially installed by free-fall penetration, and then, as it is loaded, it will rotate and dive into a position that is near normal to the anchor line. The second concept also uses free-fall penetration, but with an additional mass that is removed after it is embedded. The anchor is then used to resist lateral loads in a catenary mooring system. Novel dynamically penetrating anchors such as these will likely take on non-axisymmetric and non-planar shapes to obtain the desired hydrodynamic and embedment performance. In the case of a vertical or near-vertical mooring line, it will be necessary to predict the pull-out capacity of the anchor after it achieves its final embedment.

A review of the literature indicates that most of the studies on the pull-out capacity of horizontal plate anchors in sands have focused primarily on either circular or rectangular anchors. An early study by Ovesen (1981) suggested that circular and square anchors had comparable capacity. Subsequent studies (e.g. Murray \& Geddes, 1987; Merifield et al., 2006) have found that circular anchors have approximately 30\% higher capacity than square anchors. Other studies (e.g. Rowe \& Davis, 1982; Sing \& Ramaswamy, 2008) have shown that square anchors have higher capacities than rectangular anchors due to three-dimensional effects. The pull-out capacity of other atypical shapes is uncertain. As a starting point, the objective of this study was to investigate the pull-out capacity of shallow embedded triangleand kite-shaped anchors. Circular and square anchors are also investigated to provide a reference for comparison. 
Anchor shape effects are investigated using a combination of physical and analytical modelling as described in subsequent sections.

\section{PHYSICAL MODELLING}

Twenty small-scale $1 \boldsymbol{g}$ physical model experiments were performed on circular, square, triangular and kite-shaped anchors in dry sand, representative of drained loading conditions. The focus was on 'shallow' anchors, having an embedment ratio $(H / B)$ of less than or equal to 5 , where $H$ is the depth from the ground surface to the lowest point of the anchor and $B$ is the diameter or minimum width of the anchor. The focus on shallow embedded anchors was justified based on free-fall penetration modelling studies of plate-like anchors in sand (e.g. Gerkus et al., 2016; Chow et al., 2017).

Scale effects are important to consider in small-scale $1 \mathrm{~g}$ models so that the results can be reliably interpreted. Bradshaw et al. (2016) showed that scale effects can be minimised in $1 \boldsymbol{g}$ plate anchor tests by scaling the constitutive behaviour of the soil and by presenting the pull-out capacity in a dimensionless form, commonly referred to as a break-out factor $\left(N \gamma=q_{\mathrm{u}} / \gamma H\right)$, where $q_{\mathrm{u}}$ is the ultimate bearing capacity and $\gamma$ is the dry unit weight (or buoyant unit weight if saturated), and by scaling the constitutive behaviour of the soil. Soils exhibit higher resistance in small-scale $1 \boldsymbol{g}$ model tests due to higher dilation at low confining pressures. Bradshaw et al. (2016) concluded that the scaling of the constitutive behaviour will involve preparing the soil more loosely in the model than at full scale to obtain a similar dilation response. Consistent with centrifuge scaling laws presented in Garnier et al. (2007), experiments were also designed such that the widths of the anchors were at least 48 times the median diameter $\left(D_{50}\right)$ of the sand to ensure that there was a sufficient number of particles over the width of the plate.

A schematic representation of the anchor load test set-up is shown in Fig. 1. The sand that was used in this study was obtained from a natural deposit in Westerly, Rhode Island (Bradshaw et al., 2015, 2016) and consisted of uniform quartz grains with the index properties given in Table 1.



Fig. 1. Schematic representation of the anchor test set-up used in this study
Table 1. Properties of the sand used in this study

\begin{tabular}{l|c}
\hline Property & Value \\
\hline Maximum unit weight, $\gamma_{\max }: \mathrm{kN} / \mathrm{m}^{3}$ & $18 \cdot 1$ \\
Minimum unit weight, $\gamma_{\min }: \mathrm{kN} / \mathrm{m}^{3}$ & $14 \cdot 1$ \\
Minimum void ratio, $e_{\min }$ & $0 \cdot 44$ \\
Maximum void ratio, $e_{\max }$ & $0 \cdot 84$ \\
Mean particle size, $D_{50}: \mathrm{mm}$ & $0 \cdot 30$ \\
Specific gravity, $G_{\mathrm{s}}$ & $2 \cdot 65$ \\
Critical state friction angle, $\phi_{\mathrm{cs}}^{\prime}: \operatorname{deg}$ & $32 \cdot 3$ \\
\hline
\end{tabular}

Pull-out tests were performed on circular, square, equilateral triangle- and kite-shaped plate anchors (Fig. 2). The anchors were fabricated from $12.7 \mathrm{~mm}$ thick structural steel with the dimensions shown in Fig. 2. Pull-out loads were applied vertically to the anchors by way of a $20 \mathrm{~mm}$ wide chain attached to a pad eye mounted at the centroid of the anchors. The anchors were 'wished' into place and tested in a rigid test chamber with the cross-sectional dimensions shown in Fig. 1. The length of the test chamber was $2438 \mathrm{~mm}$.

Sand was dry pluviated using a portable device adapted from Gade et al. (2013). The pluviator consisted of a bucket attached to a flexible hose leading to a pipe containing a plate with holes and a stack of sieves (Bradshaw et al., 2016). By varying the opening size, fall height of the sand and the number of sieves, the density of the sand was easily controlled. To measure the unit weight of the deposited soil during pluviation, sand was dispensed into small containers of a known volume that were placed on the soil surface at various depths. Fig. 3 shows a typical profile of dry unit weight and corresponding relative density index $\left(I_{\mathrm{D}}\right)$, defined as $\left(e_{\max }-e\right) /\left(e_{\max }-e_{\min }\right)$, where $e_{\max }, e_{\min }$ are the maximum and minimum void ratios, and $e$ is the void ratio of the prepared sample. As shown in the figure, the relative density index was fairly uniform along the depth of the sand deposit with a coefficient of variation less than $0 \cdot 20$.

The plate anchors were spaced at least $3 B$ from the walls of the test chamber and the adjacent anchors to minimise interaction. Interaction effects on the pull-out capacity were investigated using a $304.8 \mathrm{~mm}$ and $152.4 \mathrm{~mm}$ square plate anchor placed at the same embedment ratios and different spacing from the adjacent walls of the test chamber. The larger anchor was placed a distance of approximately $1 \cdot 5 B$, while the smaller anchor was placed at a distance of approximately $3 B$. Both anchors were tested in sand with similar


Fig. 2. Shapes and dimensions of the model plate anchors used in this study 


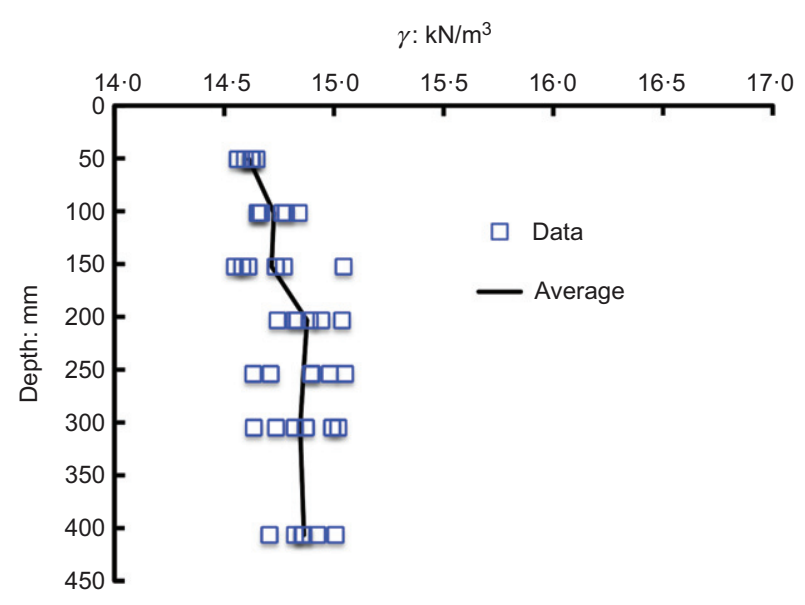

(a)

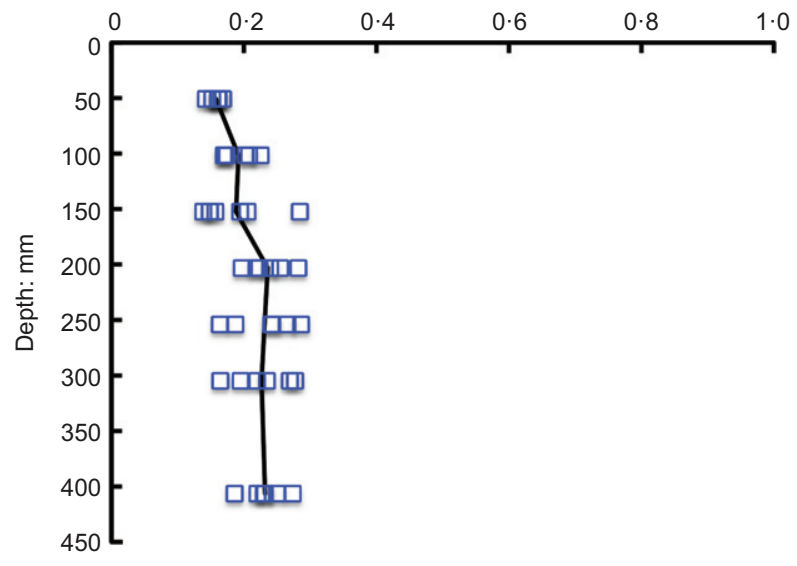

(b)

Fig. 3. Typical profiles of (a) dry unit weight and (b) relative density index obtained within the test chamber (after Bradshaw et al., 2016)

relative densities and were displaced at an identical strain rate. As discussed later, the break-out factors for both anchor tests were the same, suggesting minimal boundary and scale effects on capacity.

The anchors were displaced vertically at a constant rate of $50 \mathrm{~mm} / \mathrm{s}$ using an electric hoist, and a block and tackle system attached to the anchor chain through a load cell (Fig. 1). The displacement rate was limited by the capabilities of the hoist and was higher than other similar studies. However, strain rate effects have been shown to be negligible on the strength of dry sand (e.g. Whitman \& Healy, 1962; Bradshaw et al., 2016). The weight of the anchor plate and chain was removed from the load cell measurements so as to obtain the soil resistance. As the soil above the anchor failed as a shallow 'block', the frictional resistance of the chain was not considered as part of the pull-out resistance. The pull-out displacement was measured with a string potentiometer (Measurement Specialties SP-50).

To account for the dilation at very low stress levels in the $1 g$ physical models, the peak friction and dilation angles were estimated for each experiment using an empirical stress-dilatancy relationship proposed by Giampa \& Bradshaw (2018), which is a modification of the relationship by Bolton (1986) for very low confining pressures (i.e. $<10 \mathrm{kPa}$ ). The modified relationship is given by the following

$$
\phi_{\mathrm{p}}^{\prime}-\phi_{\mathrm{cs}}^{\prime}=A_{\mathrm{f}} I_{\mathrm{R}}
$$

Table 2. Constants needed in the modified stress-dilatancy relationship that were determined for the sand used in this study

\begin{tabular}{l|r}
\hline Parameter & Value \\
\hline$Q_{1}$ & $3 \cdot 89$ \\
$\Delta Q$ & $0 \cdot 66$ \\
$R$ & $-0 \cdot 28$ \\
$A_{\mathrm{f}}$ & $4 \cdot 75$ \\
$\beta$ & $0 \cdot 69$ \\
\hline
\end{tabular}

$$
\begin{aligned}
& \phi_{\mathrm{p}}^{\prime}-\phi_{\mathrm{cs}}^{\prime}=\beta \psi_{\mathrm{p}} \\
& I_{\mathrm{R}}=I_{\mathrm{D}}\left\{\left[Q_{1}+\Delta Q \ln \left(p_{\mathrm{f}}^{\prime}\right)\right]-\ln \left(p_{\mathrm{f}}^{\prime}\right)\right\}-R
\end{aligned}
$$

where $\phi_{\mathrm{p}}^{\prime}$ is the peak friction angle; $\phi_{\mathrm{cs}}^{\prime}$ is the critical state friction angle; $\psi_{\mathrm{p}}$ is the peak dilation angle; $p_{\mathrm{f}}^{\prime}$ is the mean effective stress at failure; $I_{\mathrm{R}}$ is the relative dilatancy index; and $Q_{1}, \Delta Q, R, A_{\mathrm{f}}$ and $\beta$ are soil-specific constants. Note that $Q_{1}$ is a value of $Q$ at $p_{\mathrm{f}}^{\prime}$ of $1 \mathrm{kPa}$. The modified relationship was calibrated for the test sand using a combination of tilt tests and triaxial tests (Giampa \& Bradshaw, 2018). The calibration parameters for the Westerly sand are shown in Table 2.

Two different relative densities of $23 \%$ and $55 \%$ were achieved in the test chamber. Although no specific prototype anchor was considered, the anchor test data would represent relative densities at the field scale that would be higher than in the models. For example, by equating the $I_{\mathrm{R}}$ in the model and prototype (Bradshaw et al., 2016), the relative density in a $2 \mathrm{~m}$ wide prototype anchor placed offshore would be approximately $26 \%$ higher than the relative density in the $1 \boldsymbol{g}$ models used in this study.

\section{PHYSICAL MODELLING RESULTS}

Figure 4 plots the normalised bearing resistance $(q / \gamma H)$ against normalised embedment for the tests performed in the sand with a dry unit weight of approximately $14.9 \mathrm{kN} / \mathrm{m}^{3}$ $\left(I_{\mathrm{D}} \sim 0 \cdot 23\right)$. The peak friction angle was interpreted to be about $38^{\circ}$ on average for these tests (Table 3). Note that the peak value of each curve in Fig. 4 is equal to $N \gamma$ as summarised in Table 3. As shown in Fig. 4, the peak resistance increases both with initial embedment and relative density regardless of the shape. All of the experimental tests show a clear peak followed by a softening behaviour, owing largely to the reduction in overburden and confining pressure as the anchor is gradually pulled out of the soil. For anchor tests starting at $H / B$ between 1 and 3 , the peak resistance occurred at approximately $0 \cdot 2 B$ of displacement relative to the initial embedment depth. Slightly more displacement (approximately $0 \cdot 5 B$ ) was required before reaching the peak resistance in the deeper anchors.

To validate the physical model results in this study, the break-out factors obtained for circular and square plate anchors are compared with data from the literature. There is an abundance of $1 \boldsymbol{g}$ model test data in the literature, mostly involving very small model anchors. As discussed by Bradshaw et al. (2016), these data may be unreliable if scaling effects are not properly accounted for. The largest concern is that the reported friction angles may not be representative of the confining pressures in the $1 g$ experiments, which could grossly underestimate the interpreted friction angle due to increased dilation at low confining pressures. Additionally, the laboratory data in these studies were generally insufficient to be able to extrapolate the 


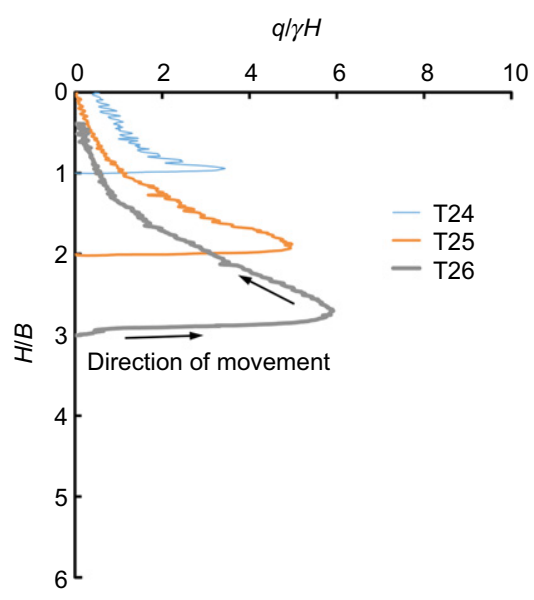

(a)

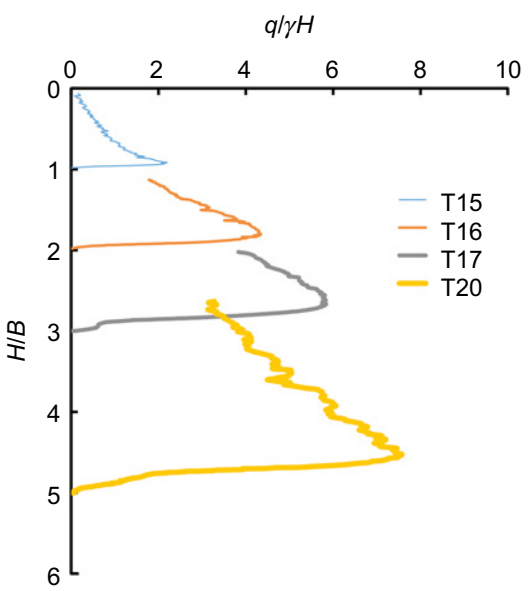

(c)

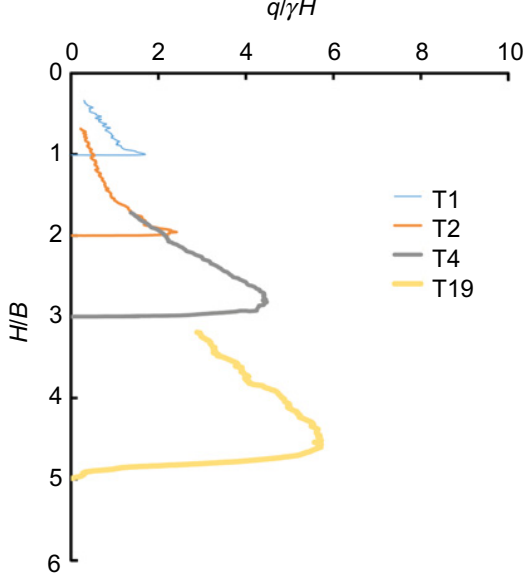

(b)

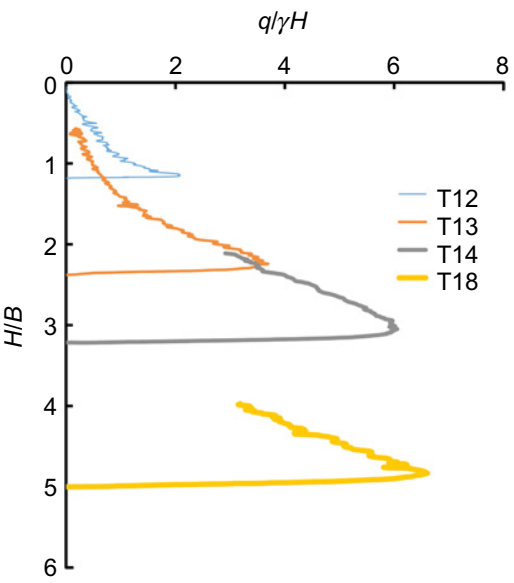

(d)

Fig. 4. Normalised load-displacement curves for the anchors with (a) circular, (b) square, (c) triangular and (d) kite shapes. The test data shown are for sand at a relative density of approximately $23 \%$ on average

Table 3. Summary of local soil properties and load test results

\begin{tabular}{|c|c|c|c|c|c|c|c|c|c|c|}
\hline Test ID & Shape & $\gamma: \mathrm{kN} / \mathrm{m}^{3}$ & $\phi_{\mathrm{p}}^{\prime}: \operatorname{deg}$ & $\psi_{\mathrm{p}}: \operatorname{deg}$ & $B: \mathrm{mm}$ & $H: \mathrm{mm}$ & $H / B$ & $q_{\mathrm{u}}: \mathrm{N}$ & $N \gamma_{\text {measured }}$ & $N \gamma_{\text {predicted }}$ \\
\hline 1 & Square & $14 \cdot 9$ & $37 \cdot 9$ & $8 \cdot 1$ & 152 & 152 & $1 \cdot 0$ & 90 & $1 \cdot 7$ & $1 \cdot 7$ \\
\hline 2 & Square & $14 \cdot 9$ & $37 \cdot 6$ & $7 \cdot 7$ & 152 & 305 & $2 \cdot 0$ & 255 & $2 \cdot 4$ & $2 \cdot 6$ \\
\hline 3 & Square & $14 \cdot 9$ & $37 \cdot 6$ & $7 \cdot 7$ & 152 & 152 & $1 \cdot 0$ & 96 & $1 \cdot 8$ & $1 \cdot 7$ \\
\hline 4 & Square & $14 \cdot 9$ & $37 \cdot 2$ & $7 \cdot 1$ & 152 & 457 & $3 \cdot 0$ & 706 & $4 \cdot 5$ & $3 \cdot 7$ \\
\hline 5 & Square & $14 \cdot 9$ & $37 \cdot 3$ & $7 \cdot 3$ & 305 & 305 & $1 \cdot 0$ & 720 & $1 \cdot 7$ & $1 \cdot 7$ \\
\hline 19 & Square & $14 \cdot 7$ & $36 \cdot 5$ & $6 \cdot 0$ & 152 & 762 & $5 \cdot 0$ & 1492 & $5 \cdot 7$ & $5 \cdot 9$ \\
\hline 15 & Triangle & $14 \cdot 8$ & $37 \cdot 1$ & $7 \cdot 0$ & 231 & 231 & $1 \cdot 0$ & 174 & $2 \cdot 2$ & $2 \cdot 3$ \\
\hline 16 & Triangle & $14 \cdot 8$ & $36 \cdot 9$ & $6 \cdot 6$ & 231 & 462 & $2 \cdot 0$ & 687 & $4 \cdot 3$ & $3 \cdot 9$ \\
\hline 17 & Triangle & $14 \cdot 8$ & $36 \cdot 7$ & $6 \cdot 4$ & 231 & 693 & $3 \cdot 0$ & 1384 & $5 \cdot 8$ & $5 \cdot 8$ \\
\hline 20 & Triangle & $14 \cdot 7$ & $36 \cdot 5$ & $6 \cdot 1$ & 127 & 635 & $5 \cdot 0$ & 494 & $7 \cdot 6$ & $10 \cdot 5$ \\
\hline 23 & Triangle & $16 \cdot 1$ & $42 \cdot 1$ & $14 \cdot 2$ & 231 & 462 & $2 \cdot 0$ & 1222 & $7 \cdot 1$ & $5 \cdot 4$ \\
\hline 12 & Kite & $14 \cdot 8$ & $37 \cdot 3$ & $7 \cdot 2$ & 196 & 236 & $1 \cdot 2$ & 173 & $2 \cdot 1$ & $2 \cdot 2$ \\
\hline 13 & Kite & $14 \cdot 8$ & $37 \cdot 0$ & $6 \cdot 8$ & 196 & 472 & $2 \cdot 4$ & 613 & $3 \cdot 7$ & $3 \cdot 8$ \\
\hline 14 & Kite & $14 \cdot 8$ & $36 \cdot 9$ & $6 \cdot 7$ & 196 & 638 & $3 \cdot 2$ & 1355 & $6 \cdot 1$ & $5 \cdot 2$ \\
\hline 21 & Kite & $16 \cdot 1$ & $42 \cdot 0$ & $14 \cdot 1$ & 196 & 472 & $2 \cdot 4$ & 1353 & $7 \cdot 6$ & $5 \cdot 3$ \\
\hline 24 & Circle & $14 \cdot 9$ & $37 \cdot 8$ & $8 \cdot 0$ & 165 & 165 & $1 \cdot 0$ & 181 & $3 \cdot 4$ & $2 \cdot 8$ \\
\hline 25 & Circle & $14 \cdot 9$ & $37 \cdot 6$ & $7 \cdot 6$ & 165 & 330 & $2 \cdot 0$ & 524 & $5 \cdot 0$ & $4 \cdot 7$ \\
\hline 26 & Circle & $14 \cdot 9$ & $37 \cdot 4$ & $7 \cdot 4$ & 165 & 495 & $3 \cdot 0$ & 935 & $5 \cdot 9$ & $6 \cdot 9$ \\
\hline
\end{tabular}

friction angle to the very low stress range. To avoid uncertainties with scale effects in the small-scale $1 \boldsymbol{g}$ test data from the literature, only centrifuge data were used for the comparisons, which included pull-out tests on circular plates in Ottawa sand (Tagaya et al., 1988) and square plates in Erith sand (Dickin, 1988). 
A comparison of the break-out factors is presented in Fig. 5. As shown in the figure, the data calculated in the present study are consistent with other studies, showing an increase in break-out factor both with increasing $H / B$ and friction angle. For the circular plates, the break-out factors from this study (Fig. 5(a)) were slightly higher but also had higher friction angles than in Tagaya et al. (1988). The test data on square plates were similar to those reported by Dickin (1988) that had comparable friction angles (Fig. 5(b)). These results provide confidence that the $1 \boldsymbol{g}$ model test data collected in this study are reasonable.

The break-out factors calculated for each anchor test are plotted in Fig. 6 against embedment ratio. In general, the measured break-out factors for circular plates were up to two times higher than square plates, which had the lowest capacity of all the shapes tested in this study. This is in general agreement with the data reported by Murray \& Geddes (1987), Tagaya et al. (1988) and Merifield et al. (2006). The capacity of the kite and equilateral triangle anchors was comparable with the square anchors at an embedment ratio of less than 2. For higher embedment ratios, the break-out factors of the kite and equilateral triangle anchors approached that of the circular plate.

To provide some insight on the failure mechanism, photographs were taken of the initial ground heave during pull-out. Fig. 7 shows the ground heave observed in anchors with $H / B=1$. The ground surface heave was not as defined in the deeper anchors. Fig. 7 suggests that the failure surface extends to the ground surface confirming a 'shallow' failure

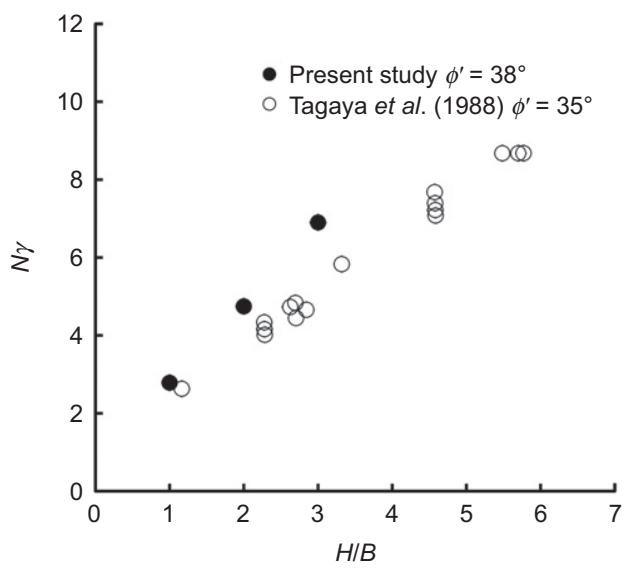

(a)

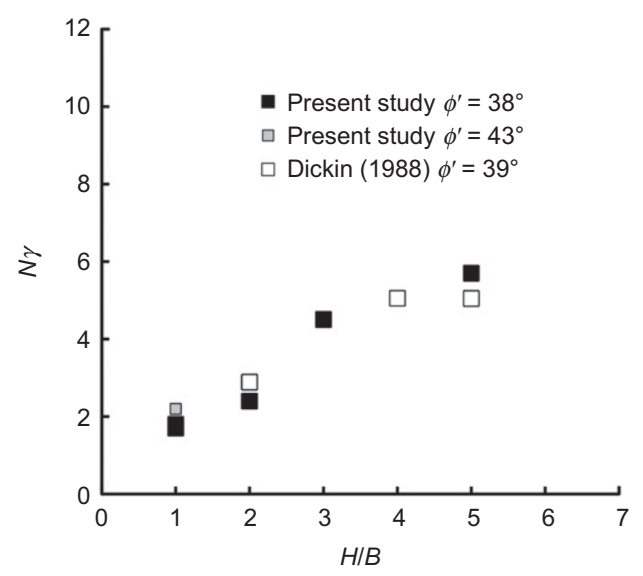

(b)

Fig. 5. Summary of experimental break-out factors for this study along with centrifuge tests from the literature for anchors with (a) circular and (b) square shapes

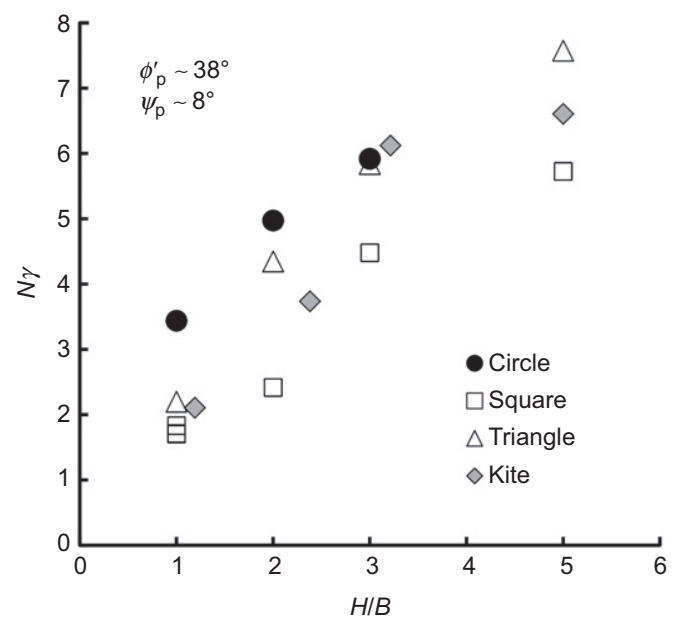

Fig. 6. Comparison of experimental break-out factors obtained in this study for various anchor shapes

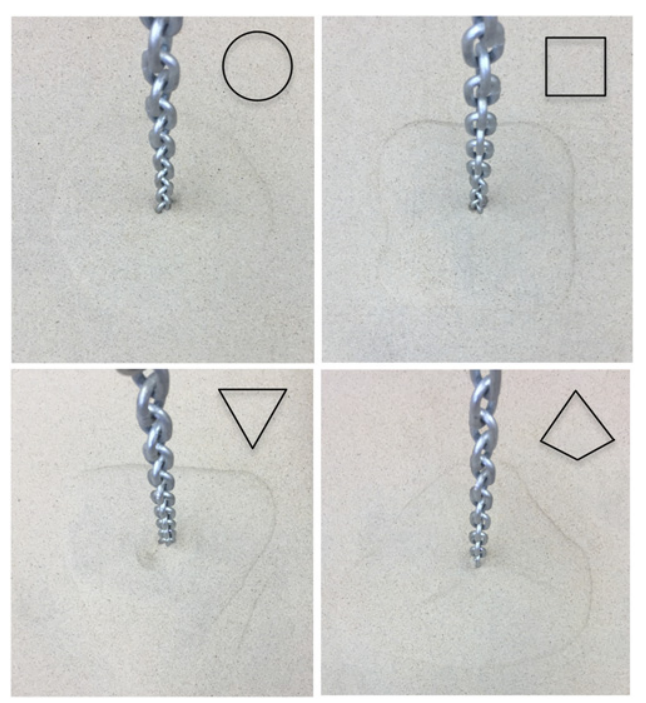

Fig. 7. Photographs taken of the initial surface heave during anchor pull-out. All anchors were embedded at an embedment ratio $(H / B)$ of approximately one

mode. The surface impressions resemble the shapes of the anchors themselves but are curved at the corners. This is consistent with observations made by Rokonuzzaman \& Sakai (2012) in both physical and numerical modelling results of shallow square plate anchors in sand.

\section{ANALYTICAL MODELLING}

Analytical modelling was also performed to assess the effects of anchor shape on capacity. Many of the available equations used to predict the pull-out capacity of plate anchors in sand are based solely on peak friction angle (Meyerhof \& Adams, 1968; Vesic, 1971; Sarac, 1989; Ghaly \& Hanna, 1994; Ilamparuthi et al., 2002; Merifield et al., 2006). These solutions are either based on the principle of associated flow, where $\psi_{\mathrm{p}}=\phi_{\mathrm{p}}^{\prime}$, or they inherently assume that the friction angle can uniquely capture the influence of dilation angle. Researchers including Davis (1968), Drescher \& Detournay (1993), Loukidis et al. (2008), White et al. (2008), Krabbenhoft et al. (2012), Sloan (2013) and Giampa et al. (2017) have shown that the assumption of associated flow does not reflect drained soil behaviour, and over-predicts 
drained foundation capacity in soils. Therefore, dilation angle should be directly included in the analysis of pull-out capacity, particularly for shallow anchors where the failure surfaces extend towards the ground surface under relatively low effective confining pressures.

To account for the effects of soil dilation in the shallow horizontal plate uplift problem, White et al. (2008) proposed a non-associated flow limit equilibrium model for plane strain conditions. In their formulation, the slip planes extend upwards from the sides of the plate to the soil surface at an angle (relative to the vertical axis) that is equal to the dilation angle of the soil. Giampa et al. (2017) extended this approach to axisymmetric conditions (i.e. circular plates). The main difference between the plane strain and axisymmetric cases was the assumption of the normal stresses on the failure surface.

A generalised non-associated flow limit equilibrium model is proposed herein that, in concept, can be applied to any convex polygon. The approach is based on the computation of the components of resistance of a three-dimensional failure 'block'. Plane strain conditions are assumed on portions of the failure surface that are planar and axisymmetric conditions are assumed on the curved portions (Rokonuzzaman \& Sakai, 2012).

A conceptual illustration of the model assumptions is shown in Fig. 8 using the square anchor as an example. Along the sides of the anchor, the model assumes that the slip surface extends up as a plane that is inclined at the dilation angle of the soil (Fig. 8(b)). At the corners, the slip surface is represented as partial cones also inclined at the dilation angle of the soil. For any convex polygon, the addition of the partial cones at the corners will form a complete cone. Therefore, the total pull-out load has three main components of resistance (Fig. 8(c)) including: $(a)$ the weight of the soil directly above the anchor; $(b)$ the weight and shear resistance of a wedge on the sides of the anchor that has a length equal to the perimeter of the anchor; and $(c)$ the weight and shear resistance of a complete cone.

The weight of soil directly above the anchor $\left(W_{1}\right)$ is given by the following equation

$$
W_{1}=\gamma H A
$$

where $\gamma$ is equal to the dry (or buoyant) unit weight; $H$ is the embedment depth of the anchor plate; and $A$ is the area of the anchor plate.

The weight of the wedges on the sides of the anchor $\left(W_{2}\right)$ is obtained from the product of the unit weight and the volume

$$
W_{2}=\frac{1}{2} \gamma H^{2} p \tan \psi_{\mathrm{p}}
$$

where $p$ is the perimeter of the anchor plate. Consistently with White et al. (2008) the normal and shear stresses acting on the slip surface at any point are given by the following equations, which assume plane strain conditions

$$
\begin{aligned}
& \sigma(z)=\gamma z\left[\frac{\left(1+K_{0}\right)}{2}-\frac{\left(1-K_{0}\right) \cos 2 \psi_{\mathrm{p}}}{2}\right] \\
& \tau(z)=\sigma(z) \tan \phi_{\mathrm{p}}^{\prime}
\end{aligned}
$$

where $\sigma$ is the normal stress on the slip plane; $\tau$ is the shear stress on the slip plane; $z$ is the depth below the ground

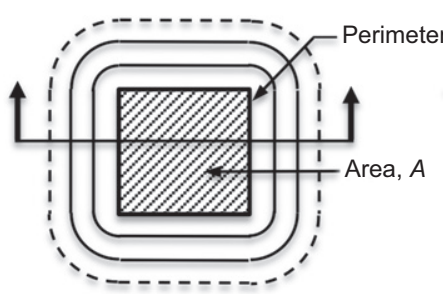

(a)

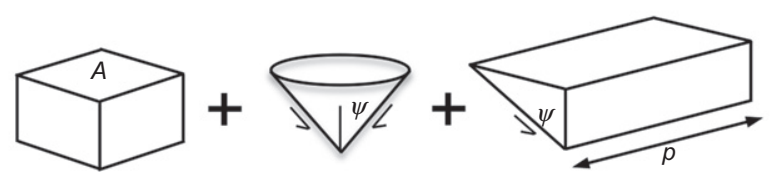

(c)

Fig. 8. Conceptual illustration showing the model assumptions for plane anchor shapes (square shown) including: (a) shape of the failure 'block' in plan view; (b) cross-section; (c) three-dimensional components of the failure 'block'

surface; and $K_{0}$ is the lateral earth pressure coefficient at rest. White et al. (2008) defined $K_{0}$ as $1-\sin \phi_{\mathrm{cs}}^{\prime}$, where $\phi_{\mathrm{cs}}^{\prime}$ is the critical state friction angle of the soil. The shear resistance of the wedge $\left(F_{2}\right)$ is obtained by integrating both the normal and shear stresses along the surface and then taking the difference between the vertical force components

$$
\begin{aligned}
F_{2}= & \frac{1}{2} \gamma H^{2} p\left(\tan \phi_{\mathrm{p}}^{\prime}-\tan \psi_{\mathrm{p}}\right) \\
& \times\left[\frac{\left(1+K_{0}\right)}{2}-\frac{\left(1-K_{0}\right) \cos 2 \psi_{\mathrm{p}}}{2}\right]
\end{aligned}
$$

The weight of the cone $\left(W_{3}\right)$ is obtained from the product of the unit weight and its volume

$$
W_{3}=\frac{1}{3} \pi \gamma H^{3} \tan \psi_{\mathrm{p}}
$$

Consistent with Giampa et al. (2017), the normal stress at any point on the slip surface of the cone is given by the following, which assumes axisymmetric conditions

$$
\sigma(z)=\gamma z \cos \left(\phi_{\mathrm{p}}^{\prime}-\psi_{\mathrm{p}}\right)
$$

The shear stress is defined by equation (7). A comparison of equation (10) with equation (6) indicates that, for normally consolidated soil, the axisymmetric assumption results in higher normal stresses on the slip surface in comparison to the plane strain assumption. The shear resistance of the cone $\left(F_{3}\right)$ is obtained by integrating both the normal and shear stresses along the lateral surface of the cone and then taking the difference between the vertical force components

$$
F_{3}=\frac{1}{3} \pi \gamma H^{3} \tan \psi_{\mathrm{p}}\left(\tan \phi_{\mathrm{p}}^{\prime}-\tan \psi_{\mathrm{p}}\right) \cos \left(\phi_{\mathrm{p}}^{\prime}-\psi_{\mathrm{p}}\right)
$$

The total pull-out force is obtained by combining equations (4), (5), (8), (9) and (11). The following nondimensional break-out factor was derived by dividing the total pull-out force by $\gamma H A$ 




(a)

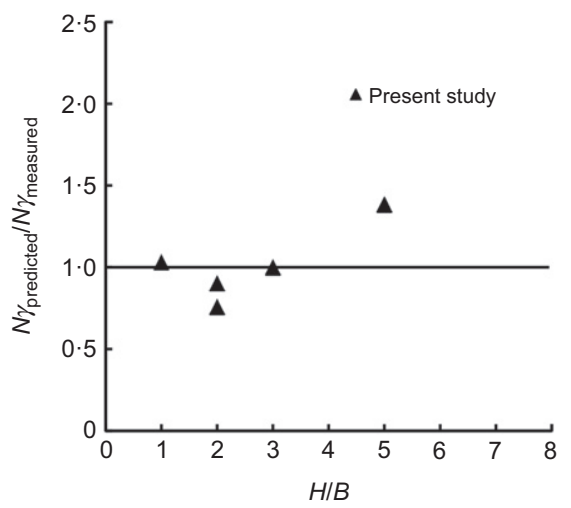

(c)

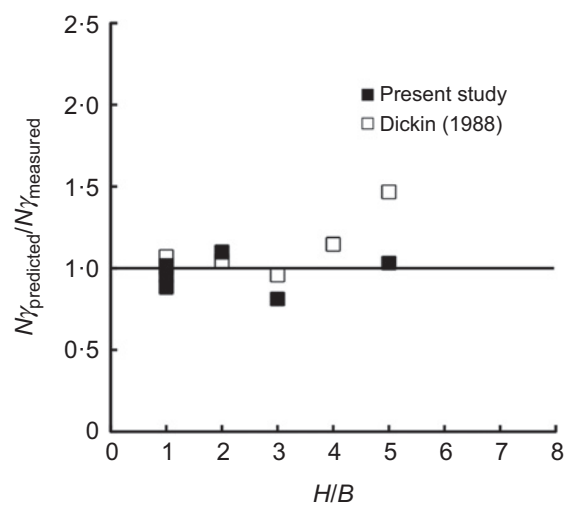

(b)

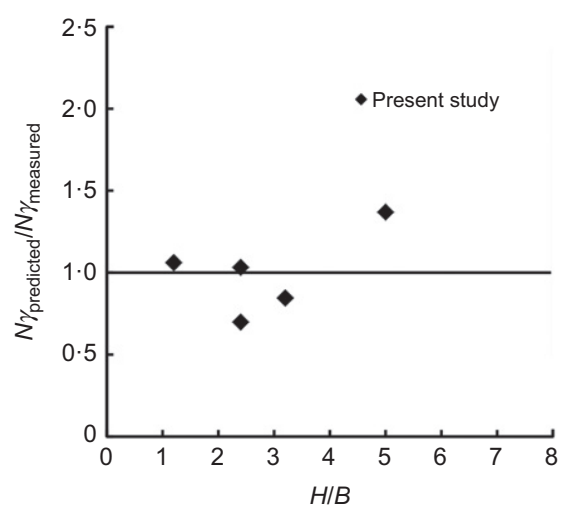

(d)

Fig. 9. Ratio of predicted to measured break-out factors for the anchors with (a) circular, (b) square, (c) triangular and (d) kite shapes

Note that equation (12) takes a very similar form to the plane strain and axisymmetric solutions given in White et al. (2008) and Giampa et al. (2017), respectively.

\section{COMPARISON OF EXPERIMENTAL AND \\ ANALYTICAL RESULTS}

The generalised non-associated flow limit equilibrium model was used to predict the break-out factors for physical model tests on square, equilateral triangle and kite anchor shapes. For comparison, the Giampa et al. (2017) model was used to predict the break-out factors for the circular plates. As discussed previously, to avoid uncertainties with scale effects in the small-scale $1 \boldsymbol{g}$ anchor test data from the literature, only the data from this study and available centrifuge data were used in the comparisons. The ratio of $N \gamma_{\text {predicted }}$ to $N \gamma_{\text {measured }}$ is plotted against $H / B$ ratio for all shapes in Fig. 9.

For the circular plates, shown in Fig. 9(a), the bias is close to unity for the shallow tests but increases almost linearly with increasing $H / B$ ratio. The skew could come from a variety of sources, including errors associated with the model assumptions for either the slip surface shape or the normal stresses on the slip surface. Another explanation could be the progressive failure of the soil along the slip surface, as discussed by Rowe \& Davis (1982) and Rokonuzzaman \& Sakai (2012). As the soil is loaded, the slip surface initially forms at the anchor location and propagates upwards toward the ground surface. In a dilative strain-softening soil, the shear stress may be at different points along the stress-strain curve. Therefore, at the peak pull-out load the shear stress on the slip surface, on average, may be lower than the peak resistance. This would result in an over-prediction in the model which assumes that the peak strength is mobilised simultaneously along the slip surface, and progressive failure
Table 4. Statistical summary of the ratio between the predicted and measured break-out factors for all tests performed as part of this study with $H I B \leq 4$. COV, coefficient of variation

\begin{tabular}{l|c|c}
\hline \multirow{2}{*}{ Shape } & \multicolumn{2}{|c}{$N \gamma_{\text {predicted }} / N \gamma_{\text {measured }}$} \\
\cline { 2 - 3 } & Mean & COV \\
\hline Circle & 1.02 & $0 \cdot 12$ \\
Square & $1 \cdot 00$ & $0 \cdot 10$ \\
Equilateral triangle & 0.92 & $0 \cdot 12$ \\
Kite & 0.91 & $0 \cdot 19$ \\
\hline
\end{tabular}

would likely be more significant as the slip surface length (i.e. embedment ratio) increases.

For the remaining shapes (Figs 9(b) to 9(d)), the generalised equation for the break-out factor provides reasonable predictions. The model is most accurate at $H / B$ ratios of 4 or less. The capacity is over-predicted by up to $40 \%$ in the tests with $H / B=5$. It is presumed that the over-prediction in the deeper anchors is associated with a departure from the model assumptions as discussed above. The average bias of all anchor shapes is presented in Table 4 , suggesting that the analytical model predictions for $H / B \leq 4$ were, on average, within $10 \%$ of the measured results.

The proposed analytical model thus provides some insight into the effects of shape on pull-out capacity. Shapes that maximise the size of the failure block as well as minimise the length of the sides (i.e. perimeter) of the shape will have the highest capacity. For example, the circular plate will have a higher capacity than a square plate with the same area. This is because, although the volume of the failure block is similar, the shallow slip surface formed in a circular plate is entirely under axisymmetric conditions. This results in higher normal 
stresses on the slip planes as compared to plane strain conditions that dominate in the square shape.

\section{SUMMARY AND CONCLUSIONS}

The objective of this study was to investigate the effect of anchor shape on the pull-out capacity of shallow embedded horizontal plate anchors in sand under drained conditions. Twenty small-scale $1 \boldsymbol{g}$ physical model experiments were performed on circular, square, equilateral triangle and kite shapes to assess the effect on pull-out capacity. The experiments accounted for scale effects. A generalised closed-form non-associated flow limit equilibrium solution was derived for convex polygon shapes. The solutions were compared to the results obtained in the physical models.

The physical model results showed that the break-out factor was highest for the circular plate anchor and lowest for the square plate. The break-out factors of the circular anchors were up to twice as high as those for the square anchors at the same embedment ratio. The break-out factors for the equilateral triangle and kite anchors fell between those for the circular and square anchors. A comparison of the analytical and experimental results indicated that the analytical model was most accurate for $H / B \leq 4$ with a bias that is within $10 \%$ on average. The model appears to capture the major components of resistance, including the weight of the failure 'block' and the shear resistance, which is influenced by the normal stress on the slip surfaces. Anchor capacity is highest in shapes (e.g. circle) that both maximise the volume of the failure block and have the largest proportions of curved failure surfaces that are under axisymmetric conditions. The results also suggest that the analytical modelling approach could be extended to shallow horizontal plate anchors having any convex polygon shape.

\section{ACKNOWLEDGEMENTS}

This material is based upon work supported by the National Science Foundation under grant no. 1300142 and also by the Science Foundation Ireland under the US-Ireland R\&D Partnership Program grant no. SFI/2012/US/E2479. The authors would like to thank the reviewers for their comments as they inspired the analytical model to be completely reformulated, which significantly improved the results. The authors would also like to thank Kevin Broccolo at the University of Rhode Island for fabricating the equipment and anchors used in this research.

$\begin{aligned} \text { NOTATION } & \\ B & \text { area of the anchor plate } \\ D_{50} & \text { diameter or minimum width of the anchor plate } \\ e & \text { void ratio } \\ e_{\max } & \text { maximum void ratio } \\ e_{\min } & \text { minimum void ratio } \\ F_{2} & \text { shear resistance of the wedge } \\ F_{3} & \text { shear resistance of the cone } \\ G_{\mathrm{s}} & \text { specific gravity } \\ H & \text { anchor embedment depth } \\ H / B & \text { embedment ratio } \\ I_{\mathrm{D}} & \text { relative density index } \\ I_{\mathrm{R}} & \text { relative dilatancy index } \\ K_{0} & \text { lateral earth pressure coefficient at rest } \\ N \gamma & \text { non-dimensional break-out factor } \\ p & \text { perimeter of the anchor plate } \\ p_{\mathrm{f}}^{\prime} & \text { mean effective stress at failure } \\ q & \text { soil-specific coefficients } \\ q & \text { bearing pressure } \\ q_{\mathrm{u}} & \text { ultimate bearing capacity } \\ W_{1} & \text { weight of soil directly above the anchor }\end{aligned}$

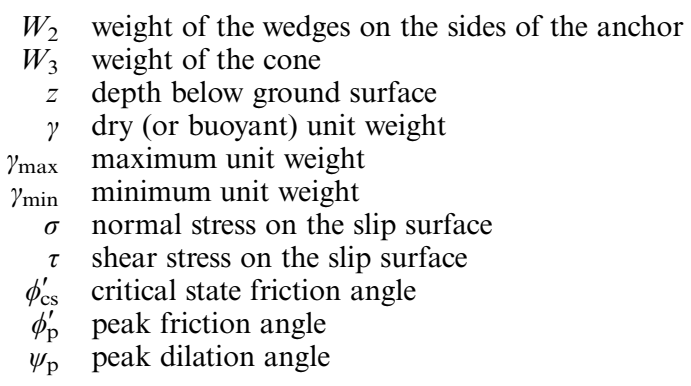

\section{REFERENCES}

Bolton, M. (1986). The strength and dilatancy of sands. Géotechnique 36, No. 1, 65-78, https://doi.org/10.1680/ geot.1986.36.1.65.

Bradshaw, A. S., Giampa, J., Dietrich, F., Gilbert, R. B. \& Gerkus, H. (2015). Pullout capacity of plate anchors in sand for floating offshore wind turbines. In Frontiers in offshore geotechnics III (ed. V. Meyer), pp. 833-838. Boca Raton, FL, USA: CRC Press.

Bradshaw, A. S., Giampa, J. R., Gerkus, H., Jalilvand, S., Fanning, J., Nanda, S., Gilbert, R., Gavin, K. \& Sivakumar, V. (2016). Scaling considerations for 1-g model horizontal plate anchor tests in sand. Geotech. Testing J. 39, No. 6, 1-9.

Chow, S. H., O'Loughlin, C. D., Gaudin, C., Knappett, J. A., Brown, M. J. \& Lieng, J. T. (2017). An experimental study of the embedment of a dynamically installed anchor in sand. Proceedings of the 8th offshore site investigation and geotechnics conference (OSIG17), London, UK, pp. 1019-1025.

Davis, E. H. (1968). Theories of plasticity and the failure of soil masses. In Soil mechanics: selected topics (ed. I. K. Lee), pp. 341-380. London, UK: Butterworths.

Dickin, E. A. (1988). Uplift behavior of horizontal anchor plates in sand. J. Geotech. Engng Div. 114, No. 11, 1300-1317.

Drescher, A. \& Detournay, E. (1993). Limit load in translational failure mechanisms for associative and non-associative materials. Géotechnique 43, No. 3, 443-456, https://doi.org/ 10.1680/geot.1993.43.3.443.

Gade, V. K., Dave, T. N., Chauhan, V. B. \& Daska, S. M. (2013). Portable traveling pluviator to reconstitute specimens of cohesionless soils. Proceedings of Indian geotechnical conference, Roorkee, India.

Garnier, J., Gaudin, C., Springman, S. M., Culligan, P. J., Goodings, D., Konig, D., Kutter, B., Phillips, R., Randolph, M. F. \& Thorel, L. (2007). Catalogue of scaling laws and similitude questions in geotechnical centrifuge modeling. Int. J. Phys. Modelling Geotech. 7, No. 3, 1-23.

Gerkus, H., Giampa, J. R., Senanayake, A. I., Lai, Y., Huang, Y., Flores, J. E. I., Breithaupt, N. B., Sivarajah, S., Bradshaw, A. S. \& Gilbert, R. B. (2016). Preliminary development of a new concept to improve sustainability of offshore foundations. In Geo-Chicago 2016: geotechnics for sustainable energy (eds A. Farid, A. De, K. R. Reddy, N. Yesiller and D. Zekkos), Geotechnical Special Publication No. 270, pp. 459-469. Reston, VA, USA: American Society of Civil Engineers.

Ghaly, A. \& Hanna, A. (1994). Ultimate pullout resistance of single vertical anchors. Can. Geotech. J. 31, No. 5, 661-672.

Giampa, J. R. \& Bradshaw, A. S. (2018). A simple method for assessing the peak friction angle of sand at very low confining pressures. Geotech. Testing J. 41, No. 4, https://doi.org/10.1520/ GTJ20170134.

Giampa, J. R., Bradshaw, A. S. \& Schneider, J. A. (2017). Influence of dilation angle on drained shallow circular anchor uplift capacity. Int. J. Geomech. 17, No. 2, 04016056.

Ilamparuthi, K., Dickin, E. A. \& Muthukrisnaiah, K. (2002). Experimental investigation of the uplift behavior of circular plate anchors embedded in sand. Can. Geotech. J. 39, No. 3, 648-664.

Jardine, R., Puech, A. \& Andersen, K. H. (2012). Cyclic loading of offshore piles: potential effects and practical design. Keynote Lecture. In Offshore site investigation and geotechnics: integrated geotechnologies - present and future (ed. P. Allan), pp. 59-100. London, UK: Society for Underwater Technology. 
Krabbenhoft, K., Karim, M. R., Lyamin, A. V. \& Sloan, S. W. (2012). Associated computational plasticity schemes for nonassociated frictional materials. Int. J. Numer. Methods Engng 90, No. 9, 1089-1117.

Loukidis, D., Chakraborty, T. \& Salgado, R. (2008). Bearing capacity of strip footings on purely frictional soil under eccentric and inclined loads. Can. Geotech. J. 45, No. 6, 768-787.

Merifield, R., Lyamin, A. \& Sloan, S. (2006). Three-dimensional lower-bound solutions for the stability of plate anchors in sand. Géotechnique 56, No. 2, 123-132, https://doi.org/10.1680/ geot.2006.56.2.123.

Meyerhof, G. \& Adams, J. (1968). The ultimate uplift capacity of foundations. Can. Geotech. J. 5, No. 4, 225-244.

Murray, E. \& Geddes, J. (1987). Uplift of anchor plates in sand. J. Geotech. Engng 3, No. 202, 202-215.

Musial, W., Butterfield, S. \& Ram, B. (2006). Energy from offshore wind. Proceedings of the offshore technology conference, Houston, TX, USA, paper OTC-18355-MS.

Musial, W. \& Ram, B. (2010). Large-scale offshore wind power in the United States. Golden, CO, USA: National Renewable Energy Laboratory.

Ovesen, N. K. (1981). Centrifuge tests of the uplift capacity of anchors. Proceedings of the 10th international conference on soil mechanics and foundation engineering, Stockholm, Sweden, pp. 717-722.

Randolph, M. \& Gourvenec, R. (2011). Offshore geotechnical engineering. New York, NY, USA: Spon Press.
Rokonuzzaman, M. \& Sakai, T. (2012). Evaluation of shape effects for rectangular anchors in dense sand: model tests and 3D finite-element analysis. Int. J. Geomech., ASCE 12, No. 2, $176-181$.

Rowe, R. K. \& Davis, E. (1982). The behaviour of anchor plates in sand. Géotechnique 32, No. 1, 25-41, https://doi.org/10.1680/ geot.1982.32.1.25.

Sarac, D. Z. (1989). The uplift capacity of shallow buried anchor slabs. In Proceedings of the 12th international conference on soil mechanics and foundation engineering, Rio de Janeiro, vol. 2, pp. 1213-1218. Rotterdam, the Netherlands: Balkema.

Sing, S. P. \& Ramaswamy, S. V. (2008). Effect of shape on holding capacity of plate anchors buried in soft soil. J. Geomech. Geoengng 3, No. 2, 157-166.

Sloan, S. W. (2013). Geotechnical stability analysis. Géotechnique 63 No. 7, 531-572, https://doi.org/10.1680/geot.12.RL.001.

Tagaya, K., Scott, R. F. \& Aboshi, H. (1988). Pullout resistance of buried anchors in sand. Soils Found. 28, No. 3, 114-130.

Vesic, A. S. (1971). Breakout resistance of objects embedded in ocean bottom. Soil Mech. Found Engng Div. 97, No. 9, 1183-1205.

White, D. J., Cheuk, C. Y. \& Bolton, M. (2008). The uplift resistance of pipes and plate anchors buried in sand. Géotechnique 58, No. 10, 771-779, https://doi.org/10.1680/geot.2008.3692.

Whitman, R. V. \& Healy, K. A. (1962). Shear strength of sands during rapid loadings. J. Soil Mech. Found. Div. 88, No. SM2, 99-131. 